\title{
Asymptomatic bronchial hyperreactivity and the development of asthma and other respiratory tract illnesses in children
}

\author{
Alan Jones
}

\begin{abstract}
Background - It is not clear whether asymptomatic bronchial hyperresponsiveness (BHR) in children is a risk factor for the subsequent development of asthma. A longitudinal study was conducted to determine the predictive value of BHR for the development of asthma in a primary care patient population.

Methods - A standard free running asthma screening test (FRAST) was applied to 956 schoolchildren aged between 4 and 11 years in 1985. Peak expiratory flow (PEF) rates were measured before hard running for six minutes and following a three minute rest period. Children with a fall in PEF of more than $15 \%$ were labelled as having a positive FRAST. Clinical data from the patients' notes and from symptom questionnaires were compared with age and sex matched controls for children known to have asthma, and for those with a positive FRAST but no asthma (BHR group). Over the ensuing six years to 1991 further clinical data were gathered to compare the development of asthma and other diseases of the airways in both the BHR groups and their controls.
\end{abstract}

Results - Of the 956 children exercised in 1985, 60 who were not known to have asthma had an abnormal test. Of the 55 of these studied in 1991, $32(58 \%)$ had developed asthma. The sensitivity of a positive FRAST for the development of asthma was $58 \%$, its specificity $97 \%$, and positive predictive value $72 \%$. Hay fever, eczema, otitis media, "bronchitis," and family history of atopy also occurred more commonly in this group.

Conclusions - Asymptomatic BHR, as shown by exercise challenge, can predict the development of clinical asthma. This study has also shown a relation between BHR, asthma, and other diseases of the airways, notably upper respiratory tract infection, "bronchitis," and otitis media.

(Thorax 1994;49:757-761)

Bronchial hyperresponsiveness (BHR) - defined as bronchi which narrow too much and too easily in response to provoking factors ${ }^{1}-$ is recognised as being clearly related to, but not identical with, asthma. It was once considered to be a fundamental part of asthma but this concept is now questioned. ${ }^{2}$ Our current know- ledge suggests that the association between BHR and asthma is incomplete, so that subjects with BHR do not always have asthma and vice versa.

It would be of interest to know whether BHR is in any way prognostic of asthma. Hopp et $a^{3}$ suggested that individuals with BHR who are entirely asymptomatic and clinically normal may represent a latent phase of asthma which may become clinically active over the course of time or under a particular stress. Other studies $^{45}$ in relatives of patients with chronic obstructive airways suggest that the presence of BHR predicts functional impairment, but this has not been substantiated by longitudinal data. There is therefore a need for longitudinal studies to be performed to characterise the temporal relation between BHR and the development of disease. $^{6}$

BHR can be measured not only in the laboratory but also in epidemiological studies. ${ }^{7-9}$ These usually entail direct inhalation challenge tests with histamine or methacholine. Indirect challenge such as exercise can also be used, and may be more specific to asthma than those of direct stimuli, but less sensitive because not all asthmatic subjects have narrowing induced by these stimuli. ${ }^{6}$ Free running is the exercise most likely to trigger asthma, ${ }^{10}$ and it was originally investigated in conditions of constant ambient temperature and humidity to minimise the coefficient of variability. ${ }^{11}$ These studies are usually recorded in hospitalised children who are often at the more severe end of the asthma spectrum. Epidemiological studies using free running asthma screening tests have been used extensively. ${ }^{12-14}$ This study describes a cohort of children studied longitudinally over five years, and looks at the predictive value of exercise induced bronchoconstriction for the development of asthma following a single screening test, and the possible relation with other diseases of the airways.

\section{Methods}

The study population initially comprised all 1357 primary school age children ( 695 boys and 662 girls) from a six partner general practice population of approximately 10000 patients in a mixed but mainly urban practice in West Glamorgan in 1985 . Of these, 58 boys $(8.5 \%)$ and 51 girls $(7.5 \%)$ had current asthma, defined as the presence of one or more of the following: (1) recurrent wheezing (other rarer causes excluded), (2) variation in rate of peak expiratory flow (PEF) of $>15 \%$ after inhaled bronchodilator challenge or in diurnal variation 
using diary cards, or (3) where any two of the six partners had used the term purely on clinical grounds within the past 12 months.

All of these children were asked to undergo a screening exercise test as previously described, ${ }^{10} 12$ involving the free running asthma screening test (FRAST). ${ }^{13}$ This was performed at 10 local primary schools on children aged 511 years $^{14}$ after obtaining ethical committee, educational system, and parental support. Children with an upper respiratory tract infection in the previous seven days were excluded and retested at a later date. Any child with a pre-exercise PEF of $20 \%$ or more below predicted values in relation to height was also excluded from the FRAST. Children were exercised in small groups using the gymnasium and all tests were carried out in June so that none were exercised in cold air $\left(<4^{\circ} \mathrm{C}\right)$.

Exercise involved running as hard as possible for six minutes to obtain a pulse rate in excess of 170 beats per minute, then resting for three minutes after which the PEF measurement was repeated. Children with asthma were not told the date of the FRAST and therefore took their asthma medication as usual. The percentage drop in PEF was categorised into $<15 \%$ (including no change and rise) or $>15 \%$. Any absentees were retested at a later date. All children with $>15 \%$ in PEF were labelled as having a positive test.

Those not known to have asthma but with a positive exercise test were categorised into an index group for positive FRAST. For each child in this group the next child listed on the school register was taken as a control. Each control was checked with the practice records for key words ${ }^{15}$ to ensure that there were no indications of undiagnosed asthma such as frequent cough, nocturnal cough, wheeze, or repeated upper respiratory tract illnesses. Each control had a negative exercise test result so that the only difference between the FRAST index and control groups was the presence of BHR as shown by the exercise test at school.

A modified form of the American Thoracic Society questionnaire ${ }^{16}$ was administered by the study nurse to the parents of the FRAST index and control groups for personal and family history of atopic characteristics and respiratory symptoms. A search was also made of the patients' notes for such events as tonsillectomy, adenoidectomy, insertion of grommets, myringotomy, referral to the outpatient clinics for whatever reason, evidence of upper respiratory tract infections, bronchitis, croup, pneumonia, otitis media, whooping cough, and any other condition of the respiratory tract. Children with chronic tonsillitis were defined as those who were either on the waiting list for tonsillectomy or had been referred for tonsillectomy.

A longitudinal follow up of the index and control groups was then made from 1985 to 1991, when again all documented evidence of asthma or upper respiratory tract illnesses was recorded prospectively. During the period prior to follow up none of the partners was aware of the exercise test results so that any subsequent diagnosis of asthma was made independently of the exercise results. Data were analysed with SPSS.PC software and the results presented as frequency distributions, estimation of cross tabulation of variables using $\chi^{2}$ estimation, and presentation of results as relevant $p$ values. The analysis of paired results was done using McNemar's test. ${ }^{17}$

\section{Results}

The overall schematic representation of the free running asthma screening test (FRAST) for the practice is shown in fig 1 . Of the total 1357 children, $956(71 \%)$ were exercised, 395 being in schools outside the practice area (private or special need schools). Six children were excluded, three with bad asthma whose initial PEF was $20 \%$ less than predicted, two with cerebral palsy, and one child with an injury. A further seven children with known asthma did not complete the test satisfactorily. This, from their comments, was due to their own fear of bronchospasm. None completed the six minutes, reached a pulse rate of 170 beats $/ \mathrm{min}$, nor showed a $>15 \%$ drop in PEF. These

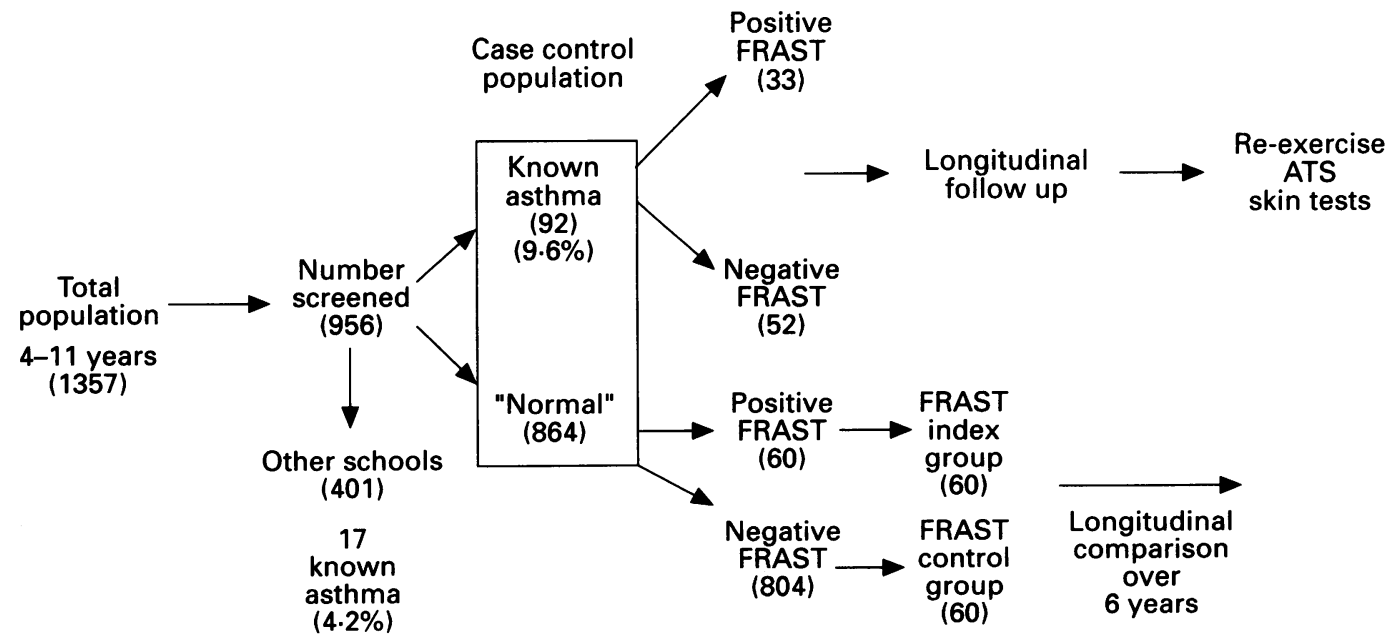

Figure 1 Schematic representation of free running asthma screening test (FRAST). ATS = American Thoracic Society questionnaire. 


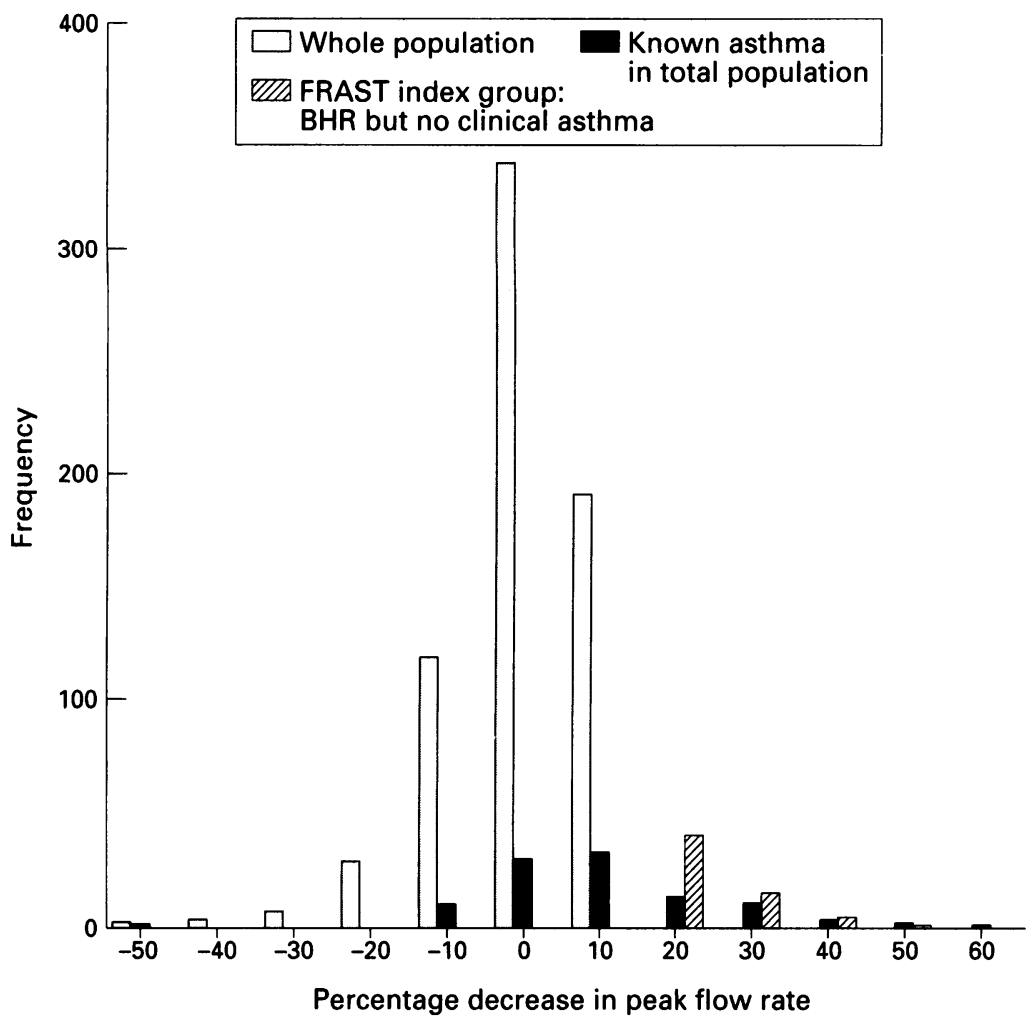

Figure 2 Overall results for all children who underwent exercise challenge test $(n=956)$. BHR $=$ bronchial hyperreactivity.

Table 1 Comparison of questionnaire analysis between the FRAST index and control groups $(n=60)$

\begin{tabular}{|c|c|c|c|}
\hline & FRAST & Control & $p$ \\
\hline \multicolumn{4}{|l|}{ Personal history } \\
\hline Eczema & 5 & 0 & $<0.05$ \\
\hline Hay fever & 11 & 8 & NS \\
\hline \multirow{2}{*}{\multicolumn{4}{|c|}{$\begin{array}{c}\text { Family history } \\
\text { Mother }\end{array}$}} \\
\hline & & & Mother \\
\hline Asthma & 5 & 1 & 0.05 \\
\hline Eczema & 3 & 7 & NS \\
\hline Hay fever & 8 & 6 & NS \\
\hline \multicolumn{4}{|l|}{ Father } \\
\hline Asthma & 3 & 4 & NS \\
\hline Eczema & 1 & 4 & NS \\
\hline Hay fever & 0 & 6 & $<0.05$ \\
\hline Grandparents & & Equal & \\
\hline Brothers & & Equal & \\
\hline Sisters & & Equal & \\
\hline \multicolumn{4}{|l|}{ Coughing history } \\
\hline Coughing with running & 15 & 5 & $<0.05$ \\
\hline Cough at night & 10 & 3 & $<0.05$ \\
\hline Cough with colds & 10 & 3 & $<0.05$ \\
\hline Cough without colds & 16 & 6 & $<0.05$ \\
\hline Cough with laughing & 8 & 6 & NS \\
\hline Cough with emotional upset & 10 & 7 & NS \\
\hline Cough with contact (e.g. dog, cat) & 10 & 8 & NS \\
\hline Wheeze from time to time & 15 & 9 & $<0.05$ \\
\hline More out of breath & 10 & 4 & $<0.05$ \\
\hline Refrain from sport & 6 & 2 & NS \\
\hline
\end{tabular}

Table 2 Comparison of questionnaire analysis between the FRAST index and control groups $(n=60)$

\begin{tabular}{lccc}
\hline & $\begin{array}{c}F R A S T \\
(n=60)\end{array}$ & $\begin{array}{c}\text { Control } \\
(n=60)\end{array}$ & $p$ \\
\hline Tonsillectomy & 1 & 0 & NS \\
Adenoidectomy & 2 & 0 & NS \\
Tonsillectomy/adenoidectomy & 1 & 2 & NS \\
Tonsillitis acute & 4 & 7 & NS \\
Tonsillitis chronic & 0 & 2 & $<0.05$ \\
Bronchitis & 10 & 3 & NS \\
Upper respiratory tract infection & 18 & 10 & NS \\
Croup & 0 & 3 & NS \\
Pneumonia & 0 & 0 & NS \\
Hearing defects & 1 & 2 & NS \\
Grommets & 2 & 0 & NS \\
Other ear operations & 3 & 1 & NS \\
Otitis media & 13 & 0 & NS \\
Serous otitis & 0 & 3 & \\
Enuresis & 3 & 0 &
\end{tabular}

children were labelled as being FRAST positive.

Of those with a positive FRAST ( $>15 \%$ fall in PEF from baseline), 93 completed the six minute test, while the remaining seven were unable to do so because of respiratory distress. Thirty three of these children ( $40 \%$ boys) had a previous diagnosis of asthma. The remainder formed the FRAST index group, of which $58 \%$ were boys. The changes in PEF recorded before and after the FRAST in the 956 children in relation to the diagnostic groups is shown in fig 2.

A comparison of the questionnaire analysis between the FRAST index and control groups is shown in table 1. All questionnaires were completed giving $100 \%$ response for the 60 pairs of children. Coughing with laughing, emotional upset, contact with dogs or cats, and refraining from sport were more common to the index group, but the differences were not statistically significant. A personal history of eczema $(p<0.05)$ and maternal history of asthma $(p<0.05)$ were significantly more common in the index group, although the reverse was true for a paternal history of hay fever. Symptoms of cough, wheeze, and breathlessness were all more frequently reported in the index group.

The comparison of the clinical conditions from the general practice notes for both FRAST index and control groups is shown in table 2. There was a trend for upper respiratory tract infections, other ear operations (myringotomy), and otitis media to occur more commonly in the FRAST group, but only the occurrence of bronchitis attained statistical significance. All these clinical conditions occurred more commonly in boys than girls - even the occurrence of bronchitis, upper respiratory tract infection, and otitis media in the control group - but none of these differences was statistically significant.

The longitudinal follow up of both FRAST and index groups from 1985 to 1991 showed that, of the 60 in the FRAST index group, five had moved from the area reducing the total to 55 in the index group. All 55 corresponding controls were still available. The comparison of the clinical data is shown in table 3. Hay fever $(p<0.01)$, eczema $(p=0.05)$, and otitis media $(p<0.05)$ all occurred more commonly in the FRAST group. Again there was a non-significant trend in the concurrent existence of upper respiratory infection, bronchitis, cough, and wheeze in this group (table 3).

Thirty two children among the index group $(58 \%)$ developed asthma over the six year follow up period, compared with only eight among the control group ( $13 \% ; \mathrm{p}<0.001)$. A prescribing pattern of asthma medication was noted both on an acute and repeat prescribing module on the practice computer for all 32 in the index group and the eight in the control group.

Of the eight children who developed asthma from the control group over the six year period six had siblings with asthma. There were no other indicators of potential asthma at the time of the first questionnaire for these eight controls. 
Table 3 Comparison of clinical conditions between FRAST index and control groups in 1991 ( $n=55$ pairs)

\begin{tabular}{lllc}
\hline & Index & Control & $p$ \\
\hline Asthma & 32 & 8 & $<0.001$ \\
Hay fever & 16 & 4 & $<0.01$ \\
Eczema & 10 & 3 & 0.05 \\
Wheeze & 7 & 3 & $\mathrm{NS}$ \\
Cough & & 2 & $\mathrm{NS}$ \\
Night & 7 & 4 & $\mathrm{NS}$ \\
Other & 8 & 7 & $<0.05$ \\
Upper respiratory tract infection/bronchitis & 15 & 6 & $\mathrm{NS}$ \\
Tonsillitis & 4 & 4 & 0.0001 \\
Medication - acute & 25 & 2 & $<0.05$ \\
Medication - repeat & 9 & 5 & $<0.05$ \\
Otitis media & 16 & 0 & $\mathrm{NS}$ \\
Family history & 5 & 1 & $\mathrm{NS}$ \\
Croup & 1 & 3 & $\mathrm{NS}$ \\
Whooping cough & 1 & 4 & $\mathrm{NS}$ \\
ENT operations & 1 & 5 & $\mathrm{NS}$ \\
Non-specific abdominal pain & 4 & 2 & \\
Headaches & 3 & &
\end{tabular}

\section{Discussion}

In the initial study there were 60 children not known to have clinical asthma but who had demonstrable BHR on exercise. Scrutiny of the practice records did not reveal any key words ${ }^{15}$ suggestive of possible underlying asthma. We tried to ensure (by asking children before the exercise test) whether they had had a recent upper respiratory tract infection (in the previous seven days), so it is unlikely that this could be an explanation to account for asymptomatic BHR. It is known that siblings of known asthmatics, who may themselves be asymptomatic, can also have a positive test. ${ }^{18}$ The questionnaire on family history, however, showed no difference in the family history of siblings in either index or control groups (table 1).

These 60 would appear, therefore, to have asymptomatic BHR. In reality, however, it could be argued that they were not truly asymptomatic as some of them had "cough" or "wheeze" (table 1), "upper respiratory tract infection" or "bronchitis" (table 2) on the questionnaire. Further subdivision of this group into those totally asymptomatic (45) and those with potentially undiagnosed asthma (15) based on symptoms could have given an even better understanding of the natural history of asymptomatic BHR. At the time of the questionnaire study, however, there were no indications on the patients' notes of these symptoms. They had to be actively sought by an interviewer-led questionnaire so that, in practice, the consulting general practitioner would not have been aided in making the diagnosis by the presence of key words. ${ }^{15} 19$

There is little to suggest that the sensitivity or specificity of the exercise test has changed with age. The sensitivity ranged from $23.5 \%$ to $50 \%$ (mean $34.4 \%$ ), being maximum in the 10 year age group. The specificity ranged from $88 \%$ to $97 \%$ (mean $92.6 \%$ ) with little measurable age dependent change. In the study by Burr et al all children were 12 years old, ${ }^{12}$ whereas the Sheffield group had a similar age range to ours, namely 4-11 years. ${ }^{13}$ There are no available data from these studies to compare the sensitivity or specificity of exercise testing with age.

Thirty three of the 92 children with known asthma had a positive test ( $>15 \%$ drop in PEF) and a further seven children were deemed to have failed the test. This shows the sensitivity of the test to be $43.5 \%$, its specificity $93 \%$, and its predictive value $40 \%$. The sensitivity of the test when the 32 who had developed asthma over the follow up period is taken into account changes to $58 \%$, the specificity to $97 \%$, and the predictive value to $72 \%$. These figures, however, do not take into account the possible number of new asthma cases which would have developed in the remaining 744 children. This compares with the low sensitivity for children found in the other studies using BHR as a screening test compared with an existing asthma diagnosis. ${ }^{6}$ The confounding effect of treatment taken by any diagnosed asthma sufferer before the test could certainly contribute to the apparently low sensitivity.

Our results are at variance with those of Balfour-Lynn et $a l^{20}$ who concluded that exercise induced bronchospasm is a sensitive indicator of clinical asthma. However, their population sample consisted of 33 hospitalised cases, whereas some of the children in our study had mild asthma and therefore it resembles more closely a whole population study than theirs. The results of the Sheffield group, ${ }^{13}$ in which 500 schoolchildren were studied, are more consistent with ours.

The changes in PEF for children who took part in the screening test showed a skew distribution to the right - that is, a decrease in PEF after exercise. The FRAST index group also showed a skew to the right but this was less pronounced than in known asthmatics. This is similar to the skew shown by Burr and workers $^{12}$ and in their study it represented children who were not current asthmatics but had wheezed at some time in the past.

The FRAST index group frequently reported the presence of cough. This is in keeping with other studies which have shown cough to be the predominant symptom of asthma, particularly in children. ${ }^{21-23}$ The "frequent cougher", rather than the "occasional wheezer", is the most likely to be missed in making the diagnosis of asthma in primary care. ${ }^{24}$ Similarly wheeze, shortness of breath, "bronchitis", "upper respiratory tract infection", and refraining from sport was more common in the BHR group. Thus, children with BHR tended to behave more like the asthma group than the controls.

During the six year follow up 32 of the remaining 55 FRAST index cases developed asthma $(58 \%)$, the diagnosis being made independently of the FRAST. These 55 again showed a trend towards a higher occurrence of upper respiratory tract infection, bronchitis, otitis media, cough, wheeze, and eczema than in the control group (table 3).

Eight children had developed asthma in the control group over the ensuing six years, six of whom had siblings with asthma. There were no other indicators of asthma or potential asthma from the notes or the questionnaire, so screening by exercise had advantages over questionnaire. A further advantage of exercise over questionnaire is that the latter relies on recall of symptoms by parents or children. It is also 
possible that feelings of pessimism or stigma may introduce recall bias in questionnaire studies.

Our data suggest a relation between upper respiratory tract illnesses in both the known asthma group and those with BHR on exercise. This association holds for conditions such as upper respiratory tract infection, bronchitis, and otitis media, although tonsillectomy, adenoidectomy, myringotomy, insertion of grommets, tonsillitis, and croup all tended to occur more commonly in these groups. The most likely reason for the significantly increased occurrence of upper respiratory tract infection or bronchitis in both the known asthma group and the FRAST index group is diagnostic transfer, but the implications for delay in asthma diagnosis by using the label "bronchitis" is again apparent. ${ }^{25}$

The label of "wheezy bronchitis" had, until recently, been abandoned because it was thought to be the cause of inappropriate delay in treatment. ${ }^{24}$ Clifford and colleagues, ${ }^{26}$ however, have returned to the possibility that, in some children, recurrent respiratory symptoms could be related to viral infections rather than atopy. The hypothesis that predisposition to developing wheezy bronchitis exists and, if atopy is additionally present, that asthma may develop was put forward by Wilson and colleagues. ${ }^{27}$ They were unable to comment as to whether this syndrome represented a distinct entity or deserved the label "asthma".

Our study confirms that of Hopp et $a l^{3}$ that BHR is not only predictive of asthma but of other diseases of the airways. Our findings are further supported by data from the National Child Development Study ${ }^{28}$ which showed similar groups of conditions to be predictive of asthma including male gender, pneumonia, whooping cough, tonsillectomy, adenvidectomy, allergic rhinitis, and eczema.

Factors that were concurrently associated with asthma included whooping cough, throat or ear infections (more than three in the past year), discharging ears, tonsillectomy, adenoidectomy, and eczema. Otitis media and nasal disease, in particular otitis media with effusion (glue ear), have an allergic basis, ${ }^{29}$ and an association between bronchiolitis, ${ }^{30}$ croup, ${ }^{31}$ chronic sinusitis, recurrent otitis media, asthma, and atopy has been reported. ${ }^{32}$

A single bronchial challenge is not necessarily a satisfactory screening test for asthma per se as it may only indicate exercise induced asthma. Nevertheless this study has shown that asymptomatic BHR can predict the development of overt asthma. The important issue as to whether asymptomatic BHR should be treated immediately is of course still open to debate, although we have shown that it predicts asthma. Whether the use of inflammatory medication would alter the progression of the disease requires further research in a randomised control trial.
The author gratefully acknowledges Professor Richard Beasley, Wellington, New Zealand for his helpful comments.

1 Woolcock AJ. What is bronchial hyperresponsiveness from the clinical standpoint? In: Page CP, Gardiner PJ, eds. Airway hyperresponsiveness: is it really important for asthma? Oxford: Blackwell Scientific Publications, 1993 chapter 1 .

2 Clough JB, Holgate S. The natural history of bronchial hyperresponsiveness. Clin Rev Allergy 1989;7:257-77.

3 Hopp RJ, Townley RG, Biven RE, Bewtra AK, Nair NM. The presence of airway reactivity before the development of asthma. Am Rev Respir Dis 1990;141:2-8.

4 Barter CE, Campbell AH. Relationship of constitutional factors and cigarette smoking to decrease in one-second forced expiratory volume. Am Rev Respir Dis 1976; 113:305.

5 Britt EB. Airways reactivity and functional deterioration in relatives of COPD patients. Chest 1980;77:260.

6 Holgate ST, Pattemore PK. Asthma in childhood. In: Page CP, Gardiner PJ, eds. Airway hyperresponsiveness: is it really important for asthma? Oxford: Blackwell Scientific Publications, 1993: 55-78.

7 Pattemore PK, Asher MI, Harrison AC, Mitchell EA, Rea $\mathrm{HH}$. The interrelationship among bronchial hyperresponsiveness, the diagnosis of asthma and asthma symptoms. $A m$ Rev Respir Dis 1990;142:549-54.

8 Salome CM, Peat JK, Britton WJ, Woolcock AJ. Bronchial hyperresponsiveness in two populations of Australian schoolchildren. I. Relation to respiratory symptoms and diagnosed asthma. Clin Allergy 1987;17:271-81.

9 Josephs LK, Gregg I, Mullee MA, Holgate ST. Nonspecific bronchial reactivity and its relationship to the clinical expression of asthma. Am Rev Respir Dis 1989;140:350-7.

10 Jones RS, Buston MH, Wharton MJ. The effect of exercise on ventilatory function in the child with asthma. $\mathrm{Br} \mathcal{F} \mathrm{Dis}$ Chest 1962;56:78-85.

11 Silverman M, Anderson SD. Standardisation of exercise tests in asthmatic children. Arch Dis Child 1972;47:882-9.

12 Burr ML, Butland BK, King S, Vaughan-Williams E. Changes in asthma prevalence: two surveys 15 years apart. Arch Dis Child 1989;64:1452-6.

13 Tsanakas JN, Milner RDG, Bannister OM, Boon AW. Free running asthma screening test. Arch Dis Child 1988;63:261-5.

14 Jones A, Bowen M. Screening for childhood asthma using exercise tolerance - lessons from primary care. $\mathrm{Br} \mathcal{f} \mathrm{Gen}$ Pract 1994;44:127-31.

15 Toop LJ. Active approach to recognising asthma in general practice. $B M \mathcal{F}$ 1985;290:1629-31.

16 American Thoracic Society. Definitions and classifications of chronic bronchitis, asthma and pulmonary emphysema. Am Rev Respir Dis 1962;85:762-8.

17 Wetherrill BG. The analysis of discrete data. In: Elementary statistical methods. 3rd edn. London: Chapman Hall, 1985.

18 Konig P, Godfrey S. Prevalence of exercise induced bronchial liability in families of children with asthma. Arch Dis Child 1973;48:513.

19 Neville RG, Bryce FP, Robertson FM, Crombie IK, Clark RA. Diagnosis and treatment of asthma in children: usefulness of a review of medical records. Br $\mathcal{F}$ Gen Pract ness of a review
1992;42:501-3.

20 Balfour-Lynn L, Tooley M, Godfrey S. Relationship of exercise-induced asthma to clinical asthma in childhood Arch Dis Child 1981;56:450-4.

21 Cloutier MM, Loughlin GM. Chronic cough in children: a manifestation of airway hyperractivity. Pediatrics 1981; 67:6-12.

$22 \mathrm{McF}$ adden ER. Exertional dyspnoea and cough as preludes to acute attack of bronchial asthma. N Engl $f \mathrm{Med}$ to acute attack

23 Spelman $R$. Chronic or recurrent cough in children - a presentation of asthma? $\mathcal{F} R$ Coll Gen Pract 1984;34:221-2.

24 Jones A, Sykes A. The effect of symptom presentation on delay in asthma diagnosis in children in general practice. Respir Med 1990;84:139-42.

25 Speight ANP, Lee DA, Hey EN. Underdiagnosis and undertreatment of asthma in childhood. BMF 1983;286:1253-6.

26 Clifford RD, Howell JB, Radford M, Holgate S. Associations between respiratory symptoms, bronchial response to methacholine and atopy in two age groups of schoolmethacholine and atopy in two age group
children. Arch Dis Child 1989;64:1133-9.

27 Wilson NM. Wheezy bronchitis revisited. Arch Dis Child 1989;64:1194-9.

28 Anderson $\mathrm{H}$, Bland J, Peckham C. Risk factors for asthma up to 16 years of age. Evidence from a national cohort study. Chest 1987;91:127-30s.

29 Fireman P. Otitis media and nasal disease: a role for allergy. $\mathcal{F}$ Allergy Clin Immunol 1988;82:917-24.

30 Henry RL, Hodges IGC, Milner AD, Stokes GM. Respiratory problems 2 years after acute bronchiolitis in infancy. Arch Dis Child 1983;58:713-6.

31 Zach MS, Schnall RP, Landau LI. Upper and lower airway hyperreactivity in recurrent croup. Am Rev Respir Dis 1980;121:979-83.

32 Shapiro GG, Virant FS, Furukawa CT, Pierson WE, Bierman CW. Immunological defects in patients with refractory sinusitis. Pediatrics 1991;87:311-6. 